Robert A. Gross, MD, PhD, FAAN

Editor-in-Chief, Neurology ${ }^{\circledR}$

Olive oil consumption, plasma oleic acid, and stroke incidence: The Three-City Study

Higher olive oil consumption and higher plasma oleic acid, a marker of oleic acid intake, were associated with lower stroke incidence in a large cohort of older subjects. This paper suggests that increasing olive oil consumption could be part of dietary recommendations to prevent stroke in the elderly. See p. 418

From editorialists Nikolaos Scarmeas and L. Dauchet: “. . . olive oil may result in neurologic health benefits. But this can be claimed with confidence only if the observations of the study by Samieri et al. withstand the trial of randomized interventions." See p. 412

\section{Statins after ischemic stroke of undetermined etiology in young adults}

This study showed that 215 young patients with a first-ever ischemic stroke, treated with a statin, had significantly lower risk of outcome events compared with those not treated, despite their poorer vascular risk factor profile. These data suggest that young patients with ischemic stroke of undetermined etiology benefit from long-term statin treatment. See p. 426

Progressive encephalomyelitis with rigidity and myoclonus: Glycine and NMDA receptor antibodies

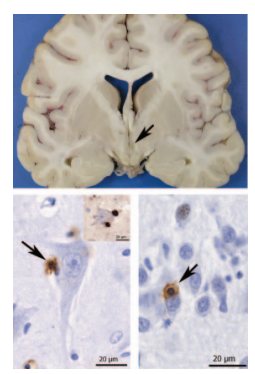

Post-mortem examination of a 28year-old man with progressive encephalomyelitis with rigidity and myoclonus revealed an autoimmune process affecting predominantly the hippocampus and cerebellum. Hyperekplexia may be an important clinical sign diagnostically, and the particularly aggressive and fatal course in this case may reflect the presence of both NMDA and glycine receptor antibodies.

See p. 439; Editorial, p. 414
Randomized, blinded trial of weekend vs daily prednisone in Duchenne muscular dystrophy 0 (1⿴囗十)

This study compared efficacy and safety of daily and weekend prednisone over 12 months in 64 boys between 4 and 10 years of age with Duchenne muscular dystrophy. Both regimens equally improved strength and function; however, pulse dosing allowed for normal linear growth while daily dosing slowed growth rate.

See p. 444; Editorial, p. 416

Early detection of Alzheimer disease: ${ }^{11} \mathrm{C}$-PiB PET in twins discordant for cognitive impairment

A cross-sectional study using ${ }^{11} \mathrm{C}$-PiB PET as a marker for amyloid accumulation was carried out with 9 monozygotic and 8 dizygotic twin pairs discordant for cognitive impairment and on 9 healthy elderly control subjects. Genetic factors appeared to influence the development of Alzheimerlike $\beta$-amyloid plaque pathology.

See p. 453

Midlife vascular risk factor exposure accelerates structural brain aging and cognitive decline

The authors assessed 1,352 subjects without dementia from the Framingham Heart study over a 10 year period. Midlife hypertension, diabetes, smoking, and obesity were associated with an increased rate of progression of vascular brain injury, global and hippocampal atrophy, and decline in executive function a decade later.

See p. 461

\section{VIEWS \& REVIEWS}

\section{Psychogenic dystonia and peripheral trauma}

Using literature review, dystonia after peripheral trauma has common clinical features, common psychogenic comorbidities, with a paucity of evidence showing neurologic mechanisms for causation. The authors' advice: look at the data! See p. 496

NB: Neurology Clinical Pathological Conference titled: "A middle-aged woman with nausea, weight loss, and orthostatic hypotension," see p. 489. To check out other publications under this subsection, point your browser to http://www.neurology.org. 


\section{Neurology}

\section{Spotlight on the August 2 Issue}

Robert A. Gross

Neurology 2011;77;411

DOI 10.1212/WNL.0b013e3182287abf

\section{This information is current as of August 1, 2011}

\section{Updated Information \&} Services

Permissions \& Licensing

Reprints including high resolution figures, can be found at: http://n.neurology.org/content/77/5/411.full

Information about reproducing this article in parts (figures,tables) or in its entirety can be found online at:

http://www.neurology.org/about/about_the_journal\#permissions

Information about ordering reprints can be found online:

http://n.neurology.org/subscribers/advertise

Neurology ${ }^{\circledR}$ is the official journal of the American Academy of Neurology. Published continuously since 1951, it is now a weekly with 48 issues per year. Copyright Copyright $@ 2011$ by AAN Enterprises, Inc.. All rights reserved. Print ISSN: 0028-3878. Online ISSN: 1526-632X.

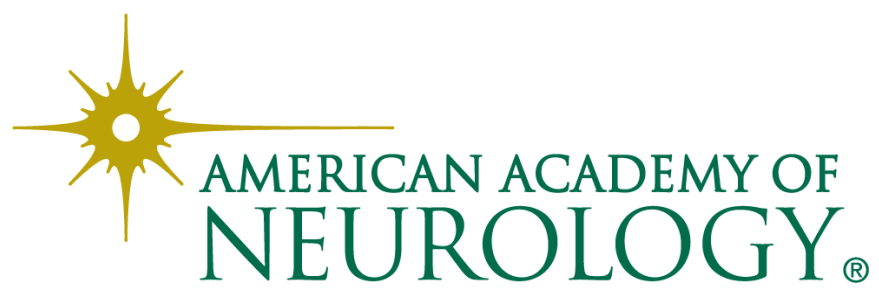

